\title{
Transformation archetypes in global food systems
}

\author{
André Zuanazzi Dornelles ${ }^{1,2}\left(\right.$. Wiebren J. Boonstra ${ }^{3,4} \cdot$ Izabela Delabre $^{5} \cdot$ J. Michael Denney $^{6} \cdot$ Richard J. Nunes $^{2}$. \\ Anke Jentsch $^{7} \cdot$ Kimberly A. Nicholas $^{8} \cdot$ Matthias Schröter ${ }^{9,10} \cdot$ Ralf Seppelt $^{10,11,12} \cdot$ Josef Settele $^{12,13,14}$. \\ Nancy Shackelford ${ }^{15} \cdot$ Rachel J. Standish ${ }^{16} \cdot$ Tom H. Oliver $^{1}$
}

Received: 12 July 2021 / Accepted: 24 January 2022 / Published online: 16 February 2022

(C) The Author(s) 2022

\begin{abstract}
Food systems are primary drivers of human and environmental health, but the understanding of their diverse and dynamic co-transformation remains limited. We use a data-driven approach to disentangle different development pathways of national food systems (i.e. 'transformation archetypes') based on historical, intertwined trends of food system structure (agricultural inputs and outputs and food trade), and social and environmental outcomes (malnutrition, biosphere integrity, and greenhouse gases emissions) for 161 countries, from 1995 to 2015 . We found that whilst agricultural total factor productivity has consistently increased globally, a closer analysis suggests a typology of three transformation archetypes across countries: rapidly expansionist, expansionist, and consolidative. Expansionist and rapidly expansionist archetypes increased in agricultural area, synthetic fertilizer use, and gross agricultural output, which was accompanied by malnutrition, environmental pressures, and lasting socioeconomic disadvantages. The lowest rates of change in key structure metrics were found in the consolidative archetype. Across all transformation archetypes, agricultural greenhouse gases emissions, synthetic fertilizer use, and ecological footprint of consumption increased faster than the expansion of agricultural area, and obesity levels increased more rapidly than undernourishment decreased. The persistence of these unsustainable trajectories occurred independently of improvements in productivity. Our results underscore the importance of quantifying the multiple human and environmental dimensions of food systems transformations and can serve as a starting point to identify potential leverage points for sustainability transformations. More attention is thus warranted to alternative development pathways able of delivering equitable benefits to both productivity and to human and environmental health.
\end{abstract}

Keywords Food systems $\cdot$ Transformations $\cdot$ Sustainable development $\cdot$ Systemic efficiency $\cdot$ Agricultural productivity

\section{Introduction}

Industrial agriculture has become a defining feature of global food systems, characterized by increased total crop yields and higher yield per input at scale. Important advancements in skills, technology, infrastructure, and trade led to increased food productivity (i.e. output in terms of weight or energy of food per unit of input invested-Benton and Bailey 2019) and enabled the expansion of global, interconnected food supply chains. The widespread premise of prioritizing yields and cheaper food to improve human

Handled by L. Jamila Haider, Stockholm Resilience Centre, Sweden.

André Zuanazzi Dornelles

a_dornelles@hotmail.com

Extended author information available on the last page of the article nutrition, however, has recently been under scrutiny due to its detrimental effects to sustainable development (Lindgren et al. 2018; Sukhdev 2018). From the perspective of the sustainable development goals (SDGs) framework, numerous synergies and trade-offs exist between the 17 goals and 169 targets for human well-being, economic prosperity, and environmental protection (Pradhan et al. 2017). Arguably, food systems are the entity that primarily connects good health and well-being (SDG 3), sustainable consumption and production (SDG 12), and life on land (SDG 15-Pradyumna 2018).

Global food systems have been failing to deliver adequate diets for everyone: an increasing prevalence of $9 \%$ of the global population is undernourished whilst, paradoxically, obesity currently affects more than $13 \%$ of individuals (FAO et al. 2020) and roughly $1 / 3$ of all food is lost or wasted (Aschemann-Witzel 2016). In around $87 \%$ of all countries 
worldwide, insufficient or excessive forms of malnutrition coexist (Development Initiatives 2020), and diet is the number one risk factor for mortality and morbidity worldwide (Afshin et al. 2019). In parallel, from production to consumption, food is responsible for $34 \%$ of anthropogenic greenhouse gas emissions (Crippa et al. 2021; Poore and Nemecek 2018) and about 70\% of freshwater use (Whitmee et al. 2015). Industrial agriculture is the prime driver of the transgression of biosphere integrity and biogeochemical flow (e.g. nitrogen deposition-Campbell et al. 2017) and, in turn, is the sector most affected by these transgressions (IPCC 2014). Increases in agricultural productivity, in this sense, have been driven by fossil fuel-based management (Ortiz-Bobea et al. 2021) and thus the notion of productivity itself needs to account for the specific indicator(s) with which the performance is measured. To transform or move away from these trajectories, it is of paramount importance to analyse the systemic patterns of change of food systems as an entry point to identify potential leverage points for sustainability transformations (Abson et al. 2017; Oliver et al. 2018).

\section{Transformation of global food systems}

The investigation of the complex and dynamic interactions driving the sustainability and efficiency of food systems from input to output remains a challenge (Hadjikakou et al. 2019; TEEB 2018). Food research is often fragmented across academic disciplines and sectors, and production or consumption stages tend to be studied in isolation from one another (Campbell et al. 2016; Dornelles et al. 2020). If metrics of health, equity, and sustainability are not embedded in a more comprehensive framework of food systems efficiency (i.e. the number of people that can be fed healthily and sustainably per unit input invested-Benton and Bailey 2019), a narrow focus on increased productivity has the potential to accelerate detrimental effects for planetary and human health in an increasingly connected world (Bahadur et al. 2018; Bengtsson et al. 2018; Seppelt et al. 2020; Willett et al. 2019). Critically, a clearer understanding of the magnitude and direction of trade-offs between food systems' productivity and key metrics is sorely needed for sustainability transformations (Fears et al. 2019; Nyström et al. 2019; Oliver et al. 2018; Pradhan et al. 2017). One way to achieve this, as we present in this study, is via an integrated model using standardized indicators to capture the multiple dimensions of food systems.

Whilst a focus on productivity of food systems has been elevated to a protagonist narrative (e.g. the claim that the world will need to produce $70 \%$ more food by 2050 has assumed unexpected tractionAlexandratos and Bruinsma 2012; Benton and Bailey 2019; Sukhdev 2018), more holistic development pathways of multiple, co-transforming environmental and social outcomes in global food systems often remain unquantified. Such social-ecological links related to food tend to be reported either in the form of states or trajectories. The state of multiple environmental, social and economic indicators across food systems have been measured cross-sectionally at different times and spaces (Chaudhary et al. 2018; Zurek et al. 2018) by the impacts of specific food types (Clark and Tilman 2017; Poore and Nemecek 2018; Springmann, et al. 2018a, b), and/or by estimates of future production hotspots or of potential mitigation measures for biosphere integrity (Springmann et al. 2018a, b; Zabel et al. 2019). In contrast, longitudinal studies track variables through time and so offer an indication to connect cause and effect, and to study trajectories. This approach has been used previously to study transformation pathways of food systems for pre-defined groups of countries (e.g. by areas of free trade or level of development-FAO 2017), for quantifying the costs and economic returns of distinct agricultural models (Ruttan 1977), for the exploration of mechanisms behind agricultural transitions (e.g. interactions between population growth and urbanizationCumming et al. 2014), or for national food indicators of socioeconomic access, biophysical capacity, and diversity of production (i.e. 'resilience indicators'-Seekell et al. 2017). As the availability of rich longitudinal datasets increases, so does the opportunity to: (1) gain an empirical understanding of intertwined rates of change within and across national food systems; (2) quantify the direction and magnitude of structure and outcome metrics under a comparable methodology; and thus to (3) specifically capture and compare the transformational feature of food systems.

\section{Methods}

\section{Overview}

Our data-driven approach to identify patterns of transformation (i.e. 'transformation archetypes') in global food systems analyses historical trends of structure metrics including agricultural inputs, outputs, and trade, and their relationship to outcomes including biosphere integrity, malnutrition (i.e. obesity and undernourishment), and greenhouse gases emissions in 161 countries, from 1995 to 2015. 'Transformation archetypes', in our study, reveal categorizations of patterns of incremental change that are suggestive of specific transition pathways, and the trajectories that these processes suggest or point to in terms of futures that may or may not be sustainable. This approach integrates statistical methods often used in ecology (e.g. cluster analysis and dissimilarity matrixes-Charrad et al. 2014) with macroeconomic measurements of trend analysis (e.g. Compound 
Annual Growth Rate; expressed as \% of annual change and reported as median and interquartile range). Our analysis assumes broadly constant compound temporal rates, which is supported by an additional analysis of five-year intervals to explore potential short-term spikes. Our approach to map the resultant archetypes of food system change with respect to co-transforming environmental, social, and economic outcomes is valuable to investigate intertwined empirical links, track the speed of progress towards desirable social-ecological goals, and also reveal watch points to potentially mitigate risks associated with the existing undesirable trajectories of change (Dornelles et al. 2020).

Our analysis of transformation archetypes in global food systems consisted of three main stages (Supplementary Figure S1): (1) data acquisition-extensive review and search; (2) data preparation-standardization and duration filters applied; and (3) data analysis-trend analysis, cluster algorithm, significance testing, and analysis of five-year intervals. All steps in data preparation and analysis were conducted in the software $\mathrm{R}$ version 3.6.1.

\section{Data acquisition}

We conducted an extensive search of publicly available repositories and official databases for comprehensive structure and outcome metrics expressing multiple aspects of agricultural production, food security and biosphere integrity related to food systems (Supplementary Table S1). Our design enabled a comparative assessment of the paradigms of interest: structure metrics are widely used as measurements of increased production (cf. paradigm of productivity), whilst the combination of structure and outcome metrics were here used to assess their links to productivity (cf. paradigm of systemic efficiency). A simplified framework of structure and outcome metrics and their connections in our integrative model is shown in Fig. 1.

Structure metrics expressed different aspects and practices related to agricultural production as a whole and related indicators of socioeconomic access, as follows: input (composed by agricultural area, synthetic fertilizer use, and agricultural employment), output (represented by gross agricultural output), productivity (quantified by agricultural total factor productivity, TFP), and economic metrics (constituted by food imports, food exports, and producer price index of agriculture). Structure metrics, as such, reveal means to achieve the ultimate function of food systems (i.e. feeding people) or are related to them as drivers or elements. Outcome metrics accounted for specific and nonspecific impacts of food systems products and/or activities in respect to biosphere integrity (expressed by the Red List Index), land-system change (covering forest area and ecological footprint of consumption), malnutrition (composed by prevalence of adult obesity and prevalence of undernourishment), and greenhouse gases emissions (including agricultural GHGE, land-use change and forestry GHGE, and the sum of agricultural, forestry, and other land-use-AFOLU GHGE; Supplementary Table S1). Outcome metrics, in this sense, express direct food-related goals for human and planetary health, proxy quantifications of such goals, and/or potential externalities from food practices. Socioeconomic

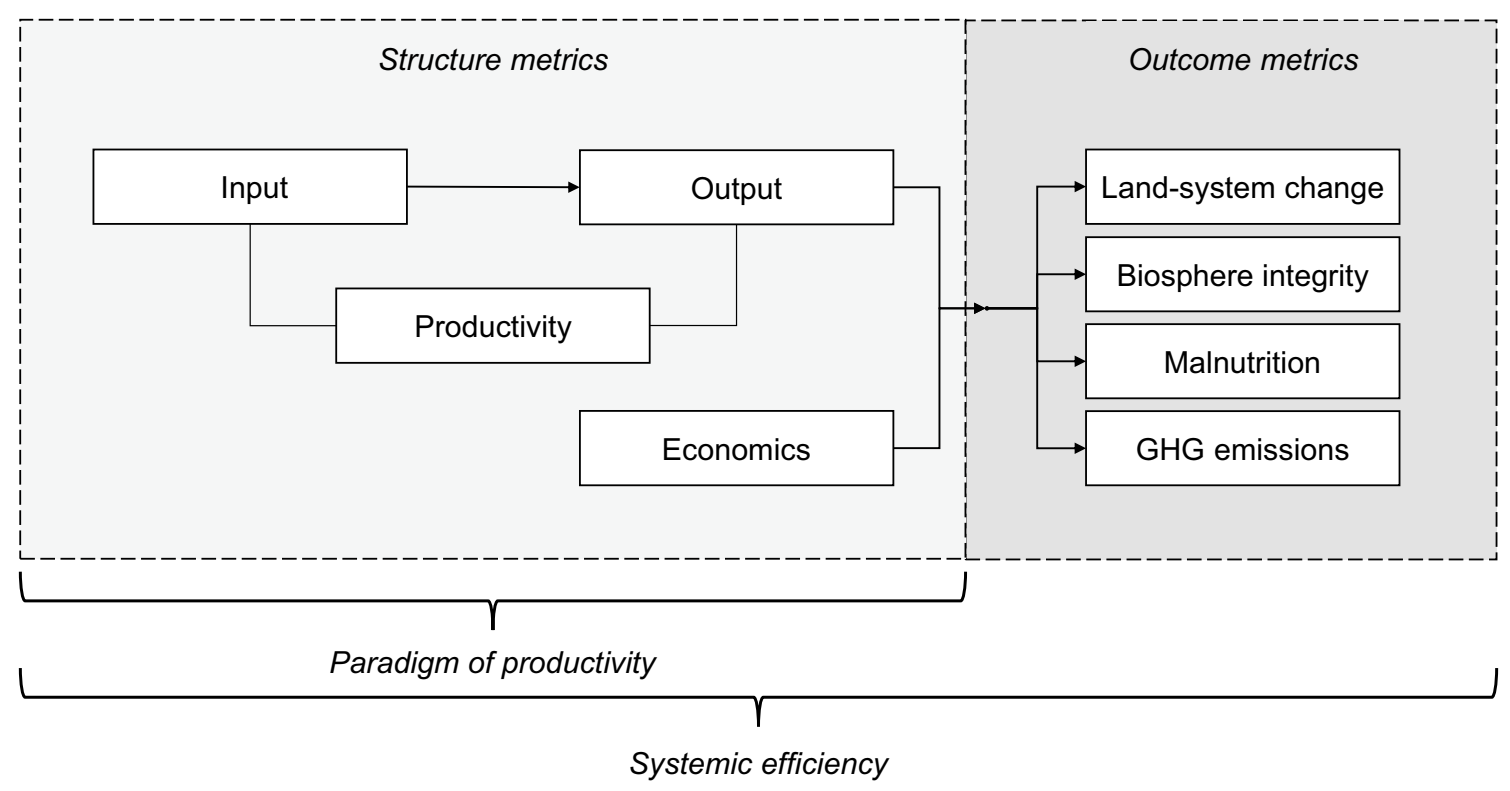

Fig. 1 Simplified framework of structure and outcome metrics and their connections in our integrative model. The structure metrics are widely used as measurements of performance of food production (cf. paradigm of productivity), whilst the combination of structure and outcome metrics were used in this study to assess their links to productivity (cf. paradigm of systemic efficiency) 
indicators were represented by income category, GDP per capita (expressed as nominal and purchasing power parity), and the Human Development Index (expressed as index and category).

Data criteria for the acquisition included attributes for length (minimum of 100 countries), time series (minimum of 10 years of measured observations, preferentially on a yearly basis), and relevance to multiple food systems stages. Twelve databases were explored from which 36 different metrics were acquired, respecting these selection criteria and described in more detail in the Supplementary Tables S2 and S3. Metadata for all metrics are available in the Supplementary materials.

\section{Data preparation}

The metrics acquired were subsequently collated into a hierarchical (i.e. individual variables, derived variables, and aggregate indicators) and standardized format by 'country', 'year', and 'value' for the longitudinal analysis. Instead of using conventional units for the state of a metric (e.g. hectares for spatial coverage, $\%$ of employment for agricultural work, or indexes for aggregated indicators), we expressed our data as annual change rate to enable a normalized comparison between distinct metrics and to specifically capture the transformational element of food systems (more details in 'trends analysis'). An exception to this approach was used for socioeconomic indicators explored in our study which, in terms of practical relevance, are categorical (e.g. income category and Human Development Index category) and cannot be expressed in \% of annual change.

We took precautions to prevent double-counting across the different hierarchies of our structure and outcome metrics. For structure metrics, we investigated how the patterns of change of raw (e.g. agricultural area) and proportional variables (e.g. agricultural employment) helped to explain wider patterns of change in one aggregate indicator in which they are embedded (e.g. productivity, TFP). All structure metrics were previously scaled and tested for correlations before the analysis of rates of co-transformation across countries (more details in 'cluster algorithm'). For outcome metrics, we explored the links between the emergent development pathways found across countries with changes in: (a) specific food-related impacts (e.g. malnutrition); (b) externalities tied to changes in structure metrics (e.g. biosphere integrity), and (c) different components of such pressures (e.g. agricultural GHGE, land-use change and forestry GHGE, and AFOLU GHGE).

The filters and duration analysis were conducted for each metric in two steps: (a) an initial filter designed to collate the metrics which met the initial criteria for acquisition (data for $\geq 100$ countries and $\geq 10$ years of observations) after the standardization stage; and (b) a refined filter programmed to extract maximum number of countries with comparable durations (i.e. number of years) and periods (i.e. in a similar time coverage) across the remaining metrics following the initial filter, covering at least $80 \%$ of the possible maximum duration for that respective window of time (see Supplementary materials; Supplementary Tables S4 and S5). In other words, the refined filter of best fit analysis was intended to assemble the metrics by the most reasonable chronological consistency, and thus avoid anachronic comparisons in duration (e.g. comparing the annual growth rate of 12 years of measured observations of one particular country with 40 years of data points of a different country) or period of coverage (e.g. juxtaposing the annual growth rate of one country from 1961 to 1981 with another country from 1991 to 2011).

\section{Data analysis}

Our data analysis consisted of four steps: (a) trend analysis, (b) cluster algorithm, (c) significance testing, and (d) analysis of five-year intervals.

\section{(a) Trends analysis}

The trend analysis was designed to assess the patterns of transformation per year in all structure and outcome metrics across countries. Following the filter of best fit indicated in the data preparation stage, the timeframe for evaluation and comparison of metrics was stipulated for the period from 1995 to 2015. In our model, we adapted the widely used equation of compound annual growth rate to estimate annualized trends in all metrics (Prajneshu and Chandran 2005). Whilst there might exist legitimate foundations for criticism on the use of empirical models assuming linear change over time (Paine et al. 2012; Prajneshu and Chandran 2005) we understand that the adjusted equation and subsequent analysis of 5-year intervals sufficiently address any potential limitations of our approach. In addition, the use of the adjusted compound annual change rate can facilitate comparison amongst multiple metrics which show varying longitudinal paths while enabling a standardized expression of change across numerous countries. The adapted equation of compound annual change rate, expressed as \% of annual change (reported in the results as median and interquartile range), was calculated taking into account the median of the first five starting values and the last five end values in order to prevent undue weight of first and last years:

End value $=$ median(last five $]$ end values)

Start value $=$ median(first five start values) 
$\mathrm{CACR}=\left(\frac{\text { End value }}{\text { Start value }}\right)^{\left(\frac{1}{\text { End value(Year)-Start value(Year) }}\right)}-1 \times 100$.

\section{(b) Cluster algorithm}

The cluster analysis computed patterns of co-transformation in five key structure metrics: agricultural area, synthetic fertilizer use, agricultural employment, gross agricultural output, and agricultural total factor productivity. These five metrics were included as the key structure metrics because of their: (a) key importance to assess the input and production stages of food systems from the paradigm of productivity; (b) relative low variance in comparison to other structure metrics (e.g. expressed by current monetary units); (c) well-established use across different disciplines in the food literature to assess different components and the efficiency of agricultural production (i.e. ratio of output per unit of input-productivity); and (d) independence (i.e. no strong pair-wise correlations were identified for the rate of change between all the five structure metrics - all Pearson's correlation scores $<0.6$ ).

Due to substantial variation in contextual drivers and states of the five key structural metrics of food systems across countries globally, we investigated potential similarities in their longitudinal change using a cluster analysis approach to be able to identify transformation archetypes. For this purpose, we used the R package NbClust (Charrad et al. 2014), which estimates the most appropriate clustering scheme and determines the number of groups for a set of different objects. The cluster algorithm runs 30 indices simultaneously, in addition to hierarchical clustering with different distance measures and aggregation methods and obtains the final result by varying all of their possible combinations. Before running the cluster analysis, we scaled the compound annual change rate of the five key structural metrics by their respective median and median absolute deviation and tested for collinearity to minimize the potential dominance of a particular set of metrics over others due to its magnitude, unit, or range. Finally, the metrics were merged into the same data frame by their scaled compound annual change rate values and only the countries with existing values for all five key structure metrics were included in the assessment by the cluster algorithm (leading to 161 countries in total). To generate the cluster dendrogram, the Euclidean distances of the dissimilarity matrix across all possible ordering of observations $\left(2^{n-1}\right)$ were used as input for the hierarchical cluster method (Ward2), which agglomerated the tightest cluster scheme possible and placed observations in order by the square root of the weighted sum of their squared distances.

\section{(c) Significance testing}

Following the allocation of countries into different groups of transformation archetypes provided by the cluster analysis, we tested for statistical differences across groups for all structure and outcome metrics by an analysis of variance model, after the implementation of the Shapiro-Wilk test of normality. Tukey's honest significance test was applied to scrutinize differences between specific groups. Statistical significance threshold was set at 0.05 .

\section{(d) Five-year intervals analysis}

As a final step, we assessed the potential for non-linearities in the temporal trends of the food system metrics used in our analysis to influence allocation of transformation archetypes. To this end, we computed the compound annual change rate of all structure and outcome metrics of each transformation archetype in sub-divided periods of five years: from 1995 to 2000; from 2000 to 2005; from 2005 to 2010; and from 2010 to 2015. Here, however, we used the conventional compound annual change rate equation of real end and start values for each five-year interval (and not the median of the first five start values and last five end values) due to the low number of observations in each interval.

Goodness of fit statistics were calculated to explore potentially more appropriate cluster composition (guided by the same absolute number of clusters reported in the main results from 1995 to 2015). Within and across cluster distances (Ward2) were extracted and the cophenetic distance was calculated to express goodness of fit (correlation between Euclidean distances in the dissimilarity matrix and the agglomeration output from the hierarchical cluster, Ward2). The cophenetic distances were broadly similar in the five-year intervals and in the main interval from 1995 to 2015 for the three transformation archetypes assessed.

\section{Results and discussion}

\section{Archetypes of change}

We identified three transformation archetypes in global food systems metrics from 1995 to 2015, as described in Box 1: (1) rapidly expansionist transformation archetype (RETA), (2) expansionist transformation archetype (ETA), and (3) consolidative transformation archetype (CTA). Evidence for the existence of three distinct transformation archetypes emerged more consistently than any other clustering across 30 different clustering indices tested (see "Methods"), with significant differences in trend metrics between the clusters supported by a post 
Box 1 Characteristics of the transformation archetypes in global food systems

Rapidly expansionist transformation archetype (RETA) countries in RETA tended to show patterns of rapid expansion in agricultural area, synthetic fertilizer use, and gross agricultural output, whilst rates of change in structure and outcome metrics commonly surpassed values of $3 \%$ per year. These patterns of rapid expansion tended to be accompanied, however, by undesirable systemic outcomes including increases in obesity, agricultural greenhouse gases emissions, and ecological footprint of consumption. The 26 countries of this archetype were most commonly from Sub-Saharan Africa and South-eastern Asia. This archetype was predominantly composed of low-income countries in 1995 $(n=19,73 \%)$ and exhibited the lowest improvement in their socioeconomic status by $2015(n=8,30.8 \%)$

Expansionist transformation archetype (ETA) this archetype often expressed intermediary rates of change between RETA and CTA, commonly surpassing rates of change of $1.5 \%$ annually. The 63 countries of this archetype were found across Asia, Africa, and Central and South America, but not North America or Western Europe. Many countries in ETA were of low and lower-middle-income category $(n=30$ and $n=27,48 \%$ and $43 \%$, respectively) and 29 of them (46\%) improved their socioeconomic condition by 2015

Consolidative transformation archetype (CTA) CTA frequently indicated relative stability in outcome metrics (e.g. rates of change commonly between- 0.5 and $0.5 \%$ per year) and the lowest rates of change in key structure metrics across transformation archetypes. Many of the 72 countries of this archetype were from North America and Europe, although some were from South America and Eastern Asia, whilst a couple of nations were from Oceania and Northern and Southern Africa. CTA expressed not only the highest ratio of high-income countries $(n=27$, $37.5 \%)$ but also of income category improvement $(n=37,51.4 \%)$

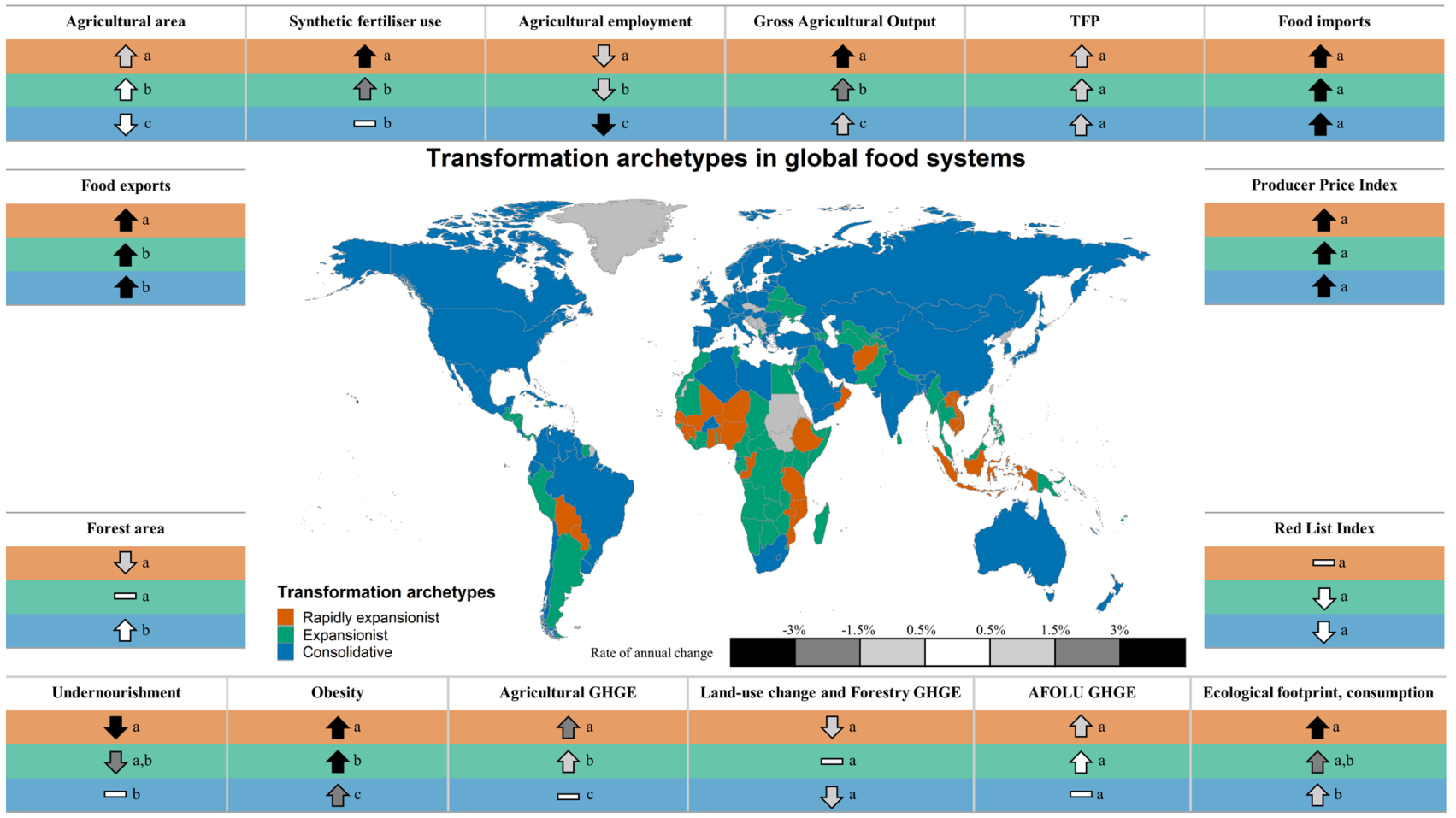

Fig. 2 Transformation archetypes affecting national food production and supply of 161 countries from 1995 to 2015 . Rate of annual change for structure metrics (on the top) and for outcome metrics (on the bottom) are measured by compound annual change rate (median, $\% / y e a r)$. Lowercase letters ' $a$ ', ' $b$ ', and 'c' besides arrows indicate significant differences from the rapidly expansionist transformation archetype (baseline reference expressed by 'a') for each metric at $p<0.05$ (e.g. 'a', 'a', and 'a' denote no difference across transformation archetypes whilst 'a', 'b', and 'c' indicate that all are different).

hoc ANOVA analysis (Supplementary Tables S6 and S7). In mapping the archetypes, we found coexistence of the three distinct transformation archetypes in neighbouring countries from South America, Sub-Saharan Africa, and South-western and South-eastern Asia (i.e. broad
Arrows pointing up show increasing trends, arrows pointing down show decreasing trends, whilst white rectangles indicate no change over time. The colouring scheme expresses magnitude of the rates of change: black colour designates rapid change ( $\geq 3 \%$ and $\leq-3 \%)$, dark grey colour reveals intermediate $(1.5-3 \%$ and -1.5 to $-3 \%)$, grey colour specifies mild $(0.5-1.5$ and -0.5 to $-1.5 \%)$, whilst white colour represents slow change $(0-0.5$ and 0 to $-0.5 \%)$. TFP Agricultural Total Factor Productivity, GHGE greenhouse gases emissions, AFOLU Agriculture, Forestry and Other Land Use

geographic regions are not homogeneous but show all three identified archetypes in close proximity; Fig. 2). Other regions such as North America, Western Europe, and North Asia tended to be more homogeneous, mainly composed by CTA. More detailed results are available in 
the Supplementary results, from the interpretation of the cluster algorithm's output (Supplementary Figures S2, S3, S4, S5, and S6) to five-year intervals analysis (Supplementary Figures S7 and S8), along with individual country profiles. Below is a high-level summary of the key results.

\section{Agricultural productivity}

Our analysis suggests substantial progress from a perspective of food production and agricultural cost-efficiency over the past two decades. Increase in agricultural total factor productivity was evident across all transformation archetypes, identified by similar annual rates of change reported as median and interquartile range (in between brackets): RETA $=0.82 \%$ (1.56\%), ETA $=1.2 \%(2.16 \%)$, and $\mathrm{CTA}=1.36 \%$ (1.29\%). Agricultural area, synthetic fertilizer use, and gross agricultural output displayed the largest rates of annual change in RETA followed by ETA then CTA (with the exception of synthetic fertilizer use, which showed similar trends between ETA and CTA; Fig. 3). Importantly, no distinctions were found across transformation archetypes in terms of agricultural area at the beginning of the analysis, expressed by percent of total land composed of agriculture: RETA $=32.44 \%(11.98 \%)$, ETA $=39.98 \%(12.23 \%)$, and $\mathrm{CTA}=42.45 \%(14.38 \%)$, suggesting that trends are independent of starting baseline of the archetypes. Agricultural employment was under the steepest annual reduction in CTA, declining $-3.11 \%(1.79 \%)$ per year, and decreased further in RETA, $-1.16 \%$ (1.62\%), than in ETA, $-0.65 \%$ (1.07\%). Agricultural total factor productivity was the only indicator amongst the key structure metrics to show no differences across the three transformation archetypes, increasing at a rate of approximately $1 \%$ per year (although productivity growth has been suggested to be deaccelerated by the effects of anthropogenic climate change, such as rise in temperature and precipitation patterns, by approximately $21 \%$ since 1961, in light of recent findings-Ortiz-Bobea et al. 2021). This progress in productivity is widely assumed to bring wider socioeconomic benefits (); Benton and Bailey 2019; Matsuyama 1992however, our analysis shows it does not reliably reflect achievements across food systems in terms of environmental sustainability, overcoming coexistent forms of malnutrition, or improvement of socioeconomic well-being (Benton and Bailey 2019; Matsuyama 1992; Seppelt et al. 2020).
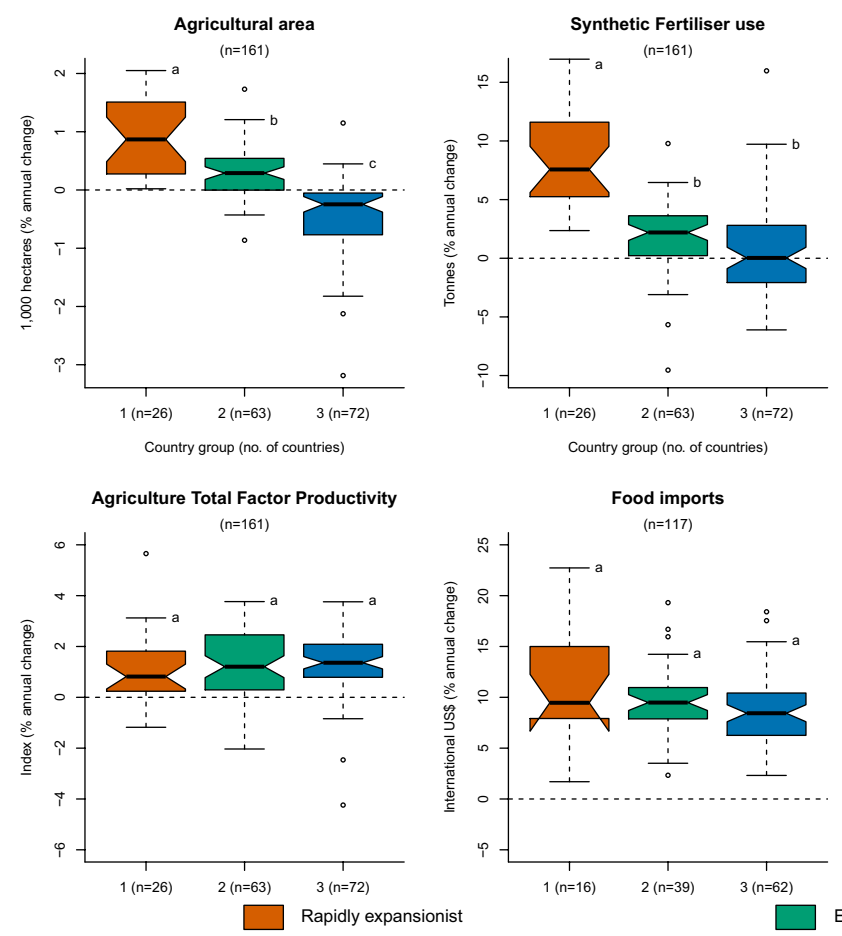

Fig. 3 Global trends in structure metrics across transformation archetypes in global food systems of 161 countries from 1995 to 2015 . Values are expressed by medians, coloured boxplot hinges indicate the range between the 1 st and 3rd quartiles, whiskers indicate 1.5 times the distance from the nearest hinge, and individual points are data observations beyond the extremes of the whiskers. Horizontal dashed lines represent absence of change (i.e. $0 \%$ annual change rate). Low-
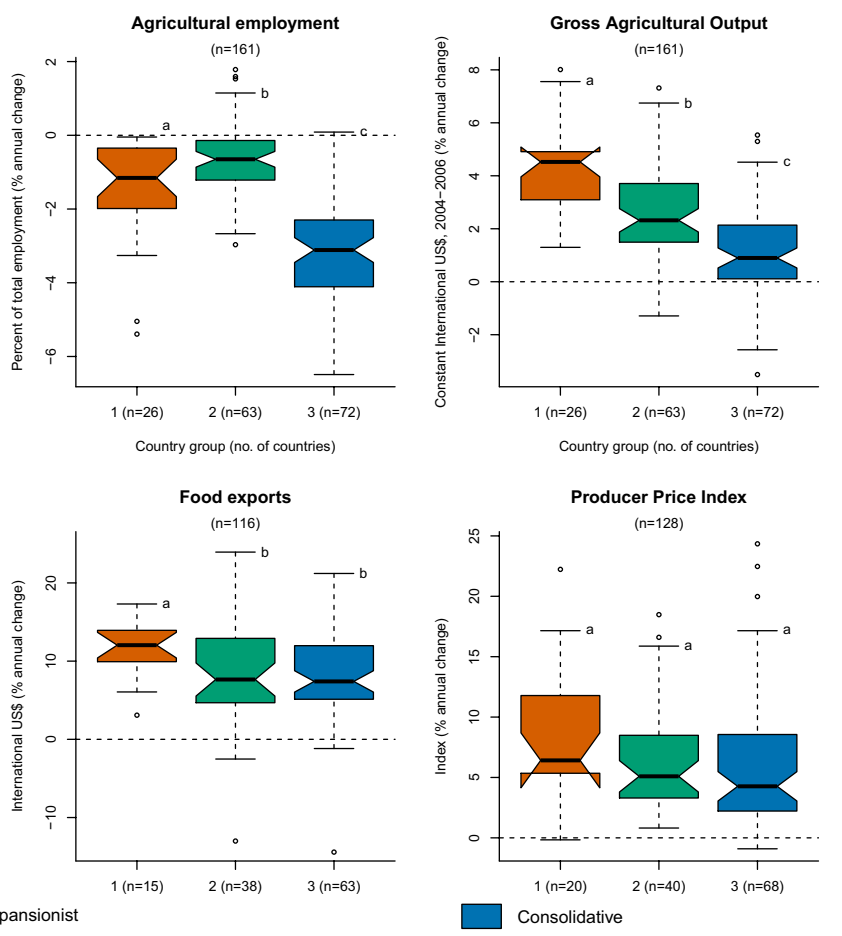

ercase letters 'a', 'b', and 'c' besides arrows indicate significant differences from the rapidly expansionist transformation archetype (baseline reference expressed by 'a') for each metric at $p<0.05$ (e.g. 'a', 'a', and ' $a$ ' denote no difference across transformation archetypes whilst 'a', 'b', and 'c' indicate that all are different). The transformation archetypes are coloured as: rapidly expansionist in vermillion, expansionist in green, and consolidative in blue 


\section{Environmental outcomes}

Concurrent with the highest rate of increase in agricultural area, RETA exhibited the greatest magnitude of change in agricultural greenhouse gases emissions (GHGE), and ecological footprint of consumption, followed by ETA, whilst CTA tended to indicate comparative stability at high absolute impact levels (Fig. 4). RETA and ETA displayed increasing rates of agricultural GHGE of $2.42 \%(1.87 \%)$ and $1.01 \%(1.68 \%)$, respectively, whilst CTA expressed virtually no change (despite showing decreasing rates of agricultural area). Ecological footprint of consumption increased more rapidly in RETA-3.05\% (1.47\%)—in comparison to CTA $-0.99 \%$ (3.08\%). Two metrics had unclear overall changes due to high variability across countries from 1995 to 2015 (GHGE from land-use change and forestry and from Agriculture, Forestry and Other Land Use-AFOLU; Supplementary Tables S6 and S7). The CT archetype manifested a slow increase in forest area of $0.12 \%(1.07 \%)$-the only environmental outcome with a higher rate of change than RETA and ETA.
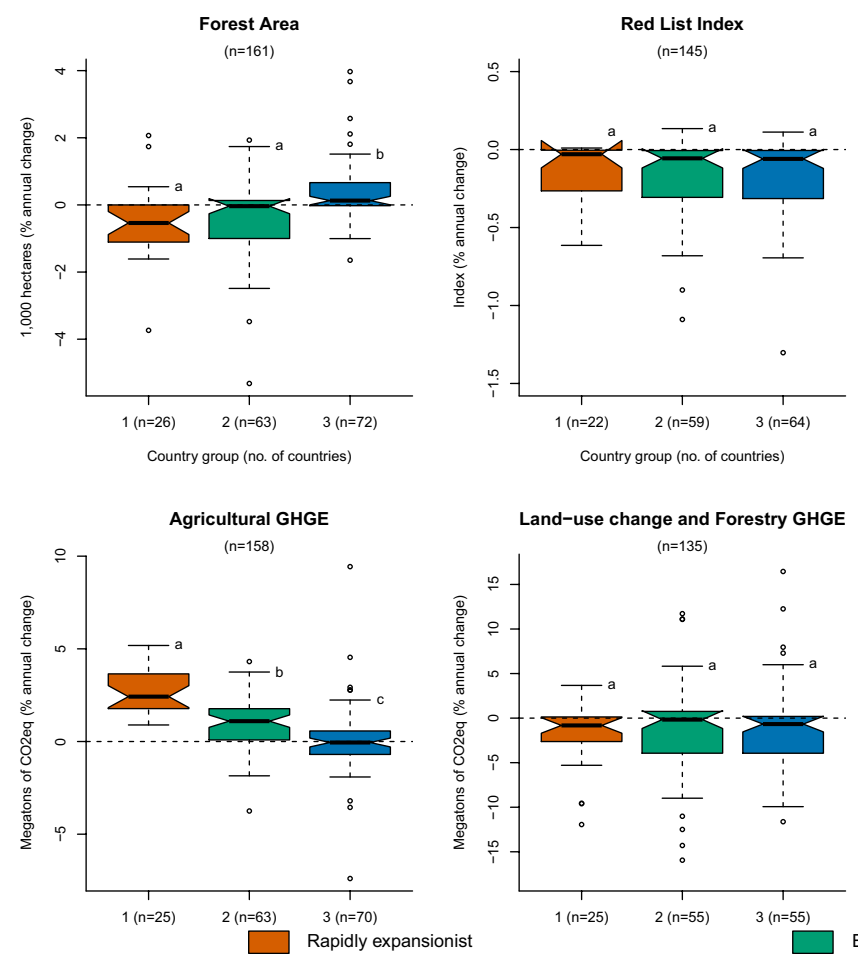

Fig. 4 Global trends in outcome metrics across transformation archetypes in global food systems of 161 countries from 1995 to 2015 . Values are expressed by medians, coloured boxplot hinges indicate the range between the 1st and 3rd quartiles, whiskers indicate 1.5 times the distance from the nearest hinge, and individual points are data points beyond the extremes of the whiskers. Horizontal dashed lines represent absence of change (i.e. $0 \%$ annual change rate). Lowercase letters 'a', 'b', and 'c' besides arrows indicate significant differences
The Red List Index exhibited slow decrease averaged across all transformation archetypes of roughly $-0.3 \%$ per year. More comprehensive assessments of biodiversity relevant to food and agriculture (e.g. pollinators, coral reefs, and soil-dwelling organisms) have reported substantial declines in vital ecosystem services over past decades, but comprehensive country level data are lacking (Beckmann et al. 2019; Pilling et al. 2020). Given the evidence of excessive chemical inputs in disrupting biogeochemical cycles (Campbell et al. 2017; Fowler et al. 2013), it is important to note the steady, high use of synthetic fertilizer in CTA and its steeply increasing use in RETA (and to some extent in ETA). CTA used an order of magnitude more synthetic fertilizer in absolute value in 1995 than ETA, and two orders of magnitude more than RETA: $\mathrm{CTA}=2.2 \times 10^{5}\left(9.5 \times 10^{5}\right)$ tonnes, $\mathrm{ETA}=2.3 \times 10^{4}$ $\left(16.3 \times 10^{4}\right)$, and RETA $=9 \times 10^{3}\left(3.8 \times 10^{4}\right)$. Thus, our analysis reveals an absence of environmental pressure alleviation in CTA (with exception to a slow increase in forest cover) in combination with rapid agricultural intensification and expansion of agricultural area (strongly
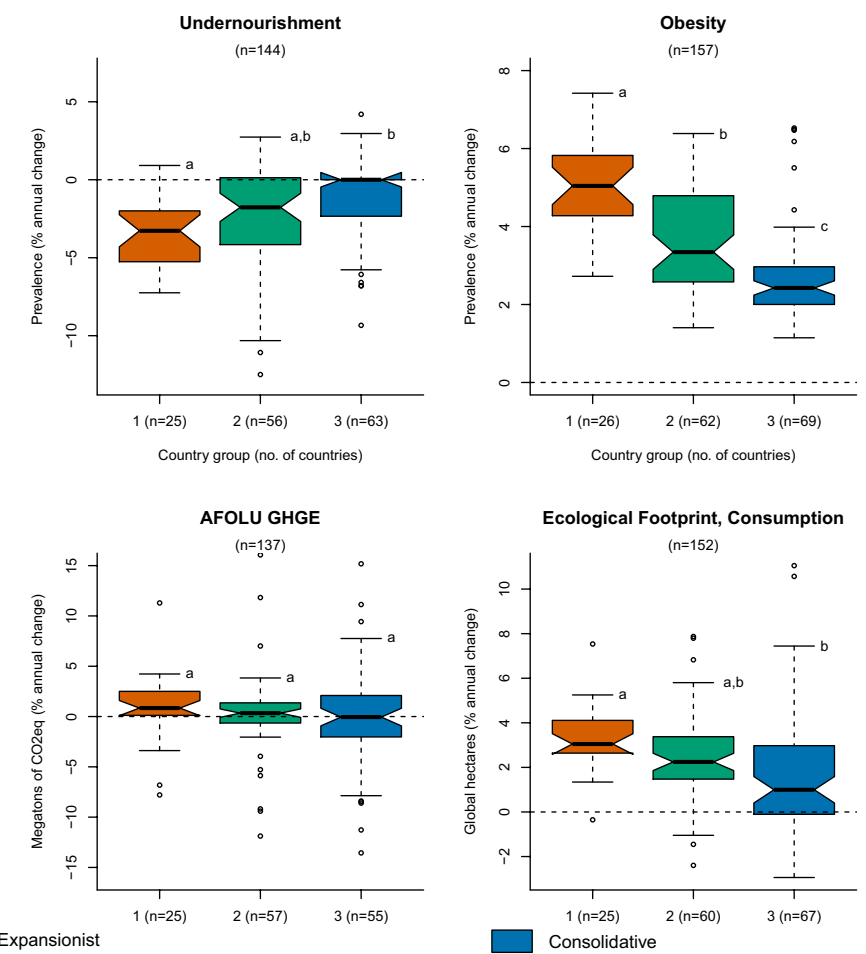

from the rapidly expansionist transformation archetype (baseline reference expressed by 'a') for each metric at $p<0.05$ (e.g. 'a', 'a', and 'a' denote no difference across transformation archetypes whilst 'a', 'b', and ' $c$ ' indicate that all are different). The transformation archetypes are coloured as: rapidly expansionist in vermillion, expansionist in green, and consolidative in blue. $G H G E$ greenhouse gases emissions, AFOLU Agriculture, Forestry and Other Land Use 
implicated in habitat loss and biodiversity decline-Schipper et al. 2020) in RETA, and to a slightly lesser extent in ETA. Collectively, these patterns unfold a worrying picture of the negative environmental impacts of recent global food system transformations.

\section{Malnourishment}

Yield growth and agricultural intensification have been widely encouraged to nourish a growing global population (Alexandratos and Bruinsma 2012; Benton and Bailey 2019), yet we found this paradigm has had only partial success in terms of mitigating coexistent forms of obesity and undernourishment over the past 20 years. Levels of undernourishment decreased substantially in the rapidly expansionist archetype and moderately in the expansionist archetype, by median rates of $-3.27 \%(3.26 \%)$ and $-1.77 \%$ (4.21\%) annually, respectively (Fig. 4). This pattern reveals remarkable progress, for instance, towards ending hunger in countries that have been most affected by food insecurity - the prevalence of undernourishment in 1995 in RETA and ETA countries was $24.7 \%$ (20.4\%) and $18.7 \%$ (19.1\%), respectively. The rate of obesity increase, however, surpassed the rate of undernourishment decrease in all archetypes. Increases in obesity were steepest in RETA, with growing prevalence of 5.04\% (1.44\%) per year, followed by the ETA with $3.34 \%(2.19 \%)$ and $2.42 \%$ (0.97\%) for CTA. Note that RETA starts from a lowest base, with obesity prevalence in 1995 in RETA, ETA and CTA, respectively, as $3.25 \%(2.6 \%), 8.75 \%$ (1.45\%), and $15 \%$ (5.7\%).

These paradoxical trends in undernourishment and obesity reveal an important challenge for the majority of countries globally, since $87 \%$ of nations currently experience double or triple burdens of malnutrition (revealed by different combinations of overweight and obesity, underweight, and/or micronutrient deficiency_FAO et al. 2019). This is particularly relevant to countries that were not able to eliminate the substantial health and social challenges from food insecurity, such as those in South America, Sub-Saharan Africa, and South-western and South-eastern Asia (Fig. 2). Simultaneous increases in obesity indicate high-levels of inequality in access to food and can overburden health systems in the pursuit of adequate prevention and treatment of non-communicable diseases attributable to dietary risks (Development Initiatives 2020). An additional consideration is the systemic effects of an increasingly interconnected global food system, whereby rapid increases in both food imports and exports across the globe suggests a pattern of increased trade dependency. Food imports increased for all archetypes by roughly $10 \%$ annually (the highest rates of change recorded across all metrics), accompanied by an equivalent increase in food exports (highest values in RETA; Fig. 3). This pattern in food trade can be seen as a double-edged sword. It can bring efficiency through comparative advantage, monetary gains for actors involved in global markets, and food diversity for many globally (Friel et al. 2020). On the other hand, trade dependency has also been suggested to be associated with potential systemic risk to environmental and economic shocks (especially in major export-oriented countries with less diversity in food production-Kummu et al. 2020), with consequent threats to populations most vulnerable to price fluctuations, seasonal shortages, and reduced nutritional quality of food baskets (Davis et al. 2021).

\section{Socioeconomic indicators}

The rate of change of GDP socioeconomic indicators tended to be independent from the transformation archetypes (Supplementary Tables S6 and S7). All transformation archetypes showed a general trend of increase in GDP per capita both for nominal and purchasing power parity: RETA $=3.5 \%$ $(10.3 \%)$ and $2.5 \%(20.4 \%), \mathrm{ETA}=1.9 \%(13.1 \%)$ and $2.1 \%$ $(10.2 \%)$, and $\mathrm{CTA}=2.8 \%$ (9.5\%) and $2.1 \%(7 \%)$. In terms of human development category (i.e. low, medium, high, or very high human development), RETA expressed, simultaneously, the biggest proportion of countries categorized as low human development in $1995(n=17 ; 81 \%)$ and the lowest ratio of improvement in human development category by $2015(n=7 ; 33.3 \%)$. ETA had a substantial proportion of countries in low and medium human development category at the beginning of the analysis $(n=25$ and $n=20 ; 53 \%$ and $42.6 \%$, respectively) and around two thirds of these countries showed improvements in their category at the end $(n=30)$. CTA, finally, exhibited the highest proportion of countries in high and very high human development categories in 1995 ( $\mathrm{n}=18$ and $\mathrm{n}=19,27.3 \%$ and $28.8 \%$, respectively) and was tied with ETA in terms of improvement of category by $2015(n=41,62 \%)$. The Human Development Index was an exemption to this general trend in socioeconomic metrics, revealed by a steeper increase in RETA than in ETA, followed by CTA: median of $1.57 \%$ ( $0.95 \%$ interquartile range), $0.97 \%(0.52 \%)$, and $0.67 \%(0.39 \%)$, respectively (Supplementary Tables S6 and S7). Although only 135 countries were measured for this metric, the proportion falling into the three respective archetypes was broadly equivalent to the full dataset: $\mathrm{RETA}=21(15.5 \%), \mathrm{ETA}=48(35.5 \%)$, and $\mathrm{CTA}=66(49 \%)$ countries.

Economic development, traditionally measured by income level (i.e. low, lower-middle, upper-middle, and high-income countries stratified by gross national income per capita), was also found to be in a converse trajectory of change to RETA and ETA. Similar to the pattern for human development category, RETA not only had the highest proportion of lowincome countries in $1995(n=19,73 \%)$, but also only 8 out of 26 countries $(30.8 \%)$ ameliorated their income category 
by 2015. Conversely, CTA displayed the highest ratio of upper-middle and high-income countries early in the analysis ( $n=13$ and $n=27,20.6 \%$ and $37.5 \%$, respectively) and, simultaneously, showed the largest improvement in income category $(n=37,51.4 \%)$. The ETA had a substantial share of countries in the low and lower-middle-income category in 1995 ( $n=30$ and $n=27,47.6 \%$ and $42.8 \%$, respectively) and 29 out of 63 countries (46\%) improved their condition by 2015 . Overall, this means that expansionist traits exhibited by archetypes of change in global food systems did not broadly reflect increased incomes (i.e. GDP per capita) and, in more practical socioeconomic terms (i.e. comparable categories of gross national income per capita), tended to be associated with persistent socioeconomic disadvantages despite increased agricultural productivity.

\section{Relevance for research and practice}

Our findings add quantitative evidence to recent qualitative assessments of food systems transformation to show that despite increases in yields and productivity, national food production and supply across the countries investigated are, in general, failing to reorient their trajectories towards nourishment of people with healthy and sustainable diets per unit input (Bahadur et al. 2018; Benton and Bailey 2019; Poore and Nemecek 2018; Springmann et al. 2018a, b; Willett et al. 2019). Our study reveals the extent of the historical and current trade-offs between food system productivity and holistic measures of food systems sustainability, and success in delivering environment, health, and other social outcomes, including how the inter-relationships diverge across countries.

Our study was designed to expand the assessment of emerging patterns in global food systems beyond linear assumptions of change over time and multidimensional analysis of single surrogate outcomes. We consequently paid crucial attention in the selection of metrics to quantify links amongst agricultural productivity, environmental pressures, malnutrition, and socioeconomic well-being. We analysed key food system structure metrics that enabled a nuanced understanding of multiple aspects of agricultural production in comparison to single metrics (e.g. 'agricultural value added per worker'). In terms of outcomes, for instance, we expressed malnutrition outcomes by prevalence of obesity and undernourishment, which are conclusive endpoints of population health and nutritional status.

Our typology explicitly links coexistent changes in food systems structure and outcomes over time and, thus, can provide a complementary and timely diagnosis to other typologies based on relative dietary energy (Fanzo et al. 2020), diversity of food supply (Bentham et al. 2020; IFPRI 2015), and the literature of food systems transformations. In addition, our study provides longitudinal insights to important cross-sectional advancements in the field of research. Marshall et al. (2021), after an extensive search of food systems typologies in the literature, investigated key metrics that lie between food productivity and nutritional outcomes, such as food environments (e.g. quantity of supermarkets and diversity of food) and consumer-related factors (e.g. percentage of urban population). They observed five food system types, with salient similarities to our findings: rural and traditional; informal and expanding; emerging and diversifying; modernizing and formalizing; and industrial and consolidated. Collectively, these categories evince the potential to serve as a useful tool to simplify some of the complexity of global food systems with comparable groups and can assist in the initial steps to design strategies and policies for sustainable and healthy transitions.

\section{Reflections on our approach}

Our typology is one of 'requisite simplicity' (Stirzaker et al. 2010)-we have uncovered important longitudinal differences across the globe spanning multiple countries and contrasted these findings with paradigms of productivity (i.e. production output per unit of input) and of systems efficiency and sustainability (i.e. the social, environmental, and economic links to optimized productivity). In doing so we have followed geopolitical boundaries and so excluded potential within-country diversities. This is the first limitation of our approach as it masks meaningful heterogeneity within food systems. However, we argue that by focusing on key geopolitical units, our typology can be used to inform national policymaking and international governance to leverage change in food systems (Abson et al. 2017). Secondly, we quantify and report our results under a general umbrella of agricultural production. We do not consider the details of different food types or groups (e.g. distinct structure and social-ecological outcomes amongst crops, livestock, or horticultural systems) because: (a) previous studies are already available for this level (Poore and Nemecek 2018; Springmann et al. 2018a, b); and (b) in this study, we want to provide a holistic, quantitative, and complementary diagnosis of global food systems diversity to the literature on food systems transformations. Thirdly, the sample metrics included in our model, and its period of assessment between 1995 and 2015, are a result of limitations in the availability and quality of the datasets explored. Other potentially relevant metrics for our research problem were either excluded from our study due to insufficient observations (e.g. pesticide use) or unavailable for a reasonably long time to allow a longitudinal analysis (e.g. food loss and waste). Broader methodological reflections are elaborated in the Supplementary materials (Methodological reflections).

Despite these limitations, we have identified 'progress' in many metrics of food systems across a vast number of 
countries globally in the past two decades. However, this notion of progress, narrowly defined in terms of higher agricultural output or improved cost-efficiency of production, was broadly independent from (or even counter to) the ability of global food systems to mitigate coexistent forms of malnutrition, pressures to planetary boundaries, or socioeconomic vulnerabilities. By quantifying the contrasts between development pathways across national food production and trade settings, we can track the otherwise complex process of change of dynamic empirical social-ecological interactions. The distinctions our method and analysis identified are valuable because they: (a) show patterns of incoherence between expected food system provisions (i.e. goals and aspirations) and what they actually deliver more explicitly (Poore and Nemecek 2018; Springmann et al. 2018a, b); and (b) reveal multiple pathways for food system development, which highlights that the future is not deterministic.

\section{Conclusions}

Our analysis shows that under current trajectories of change, dominant paradigms of food production and productivity that focus on higher yields alone are not only insufficient to achieve global goals (e.g. ending hunger or limiting global warming to $1.5^{\circ} \mathrm{C}$-Pradhan et al. 2017), but they can also hamper the attainment of other goals indirectly (e.g. health system costs for reasonable prevention and treatment of dietrelated non-communicable diseases-Development Initiatives 2020). Our conceptual design and quantitative assessment constitute a novel entry point for exploring intertwined dynamics relevant to the sustainability of food systems, in particular for a better understanding of their temporal patterns. Given the nutritional, environmental and socioeconomic trajectories revealed, a step change in strategies is likely needed to make progress that includes: (a) sustainability of agriculture (e.g. no-till and precision agriculture, reduced reliance on synthetic fertilizers), (b) resilience of supply chains (e.g. assessment of shocks to food production and their propagation or attenuation effects to food consumption and nutritional outcomes), (c) 'intent' and 'design' of leverage points for sustainability transitions (e.g. awareness of people's connections to nature and expansion of knowledge production and use with a focus on full food baskets), and (d) educational, economic, and environmental policies towards plant-based diets (Abson et al. 2017; Davis et al. 2021; Nyström et al. 2019; Poore and Nemecek 2018; Springmann et al. 2018a, b).

Our systemic approach can help to inform multiple decision-making jurisdictions about the systemic nature of increasingly interconnected global food supply chains and, at the same time, invites innovative reflections for envisioning, implementing, and evaluating sustainability transitions in food systems (Oliver et al. 2021). These intertwined relations inherently raise questions about equity and power dynamics across nations, which can impair collaboration and constrain systems transformation in decision-making platforms if disregarded (Dornelles et al. 2020). Our assessment of pace, direction, and scale of multiple coexistent metrics enables an examination of ongoing and long-term patterns often neglected in favour of 'safer' judgments about isolated, individual risks in the short term. Thus, our typology can help to reveal early stages of opportunities and constraints related to leverage points to sustainability transformations.

Essentially, the interdependence across global food systems requires policies which are consistent with the empirical trajectories of structure and outcome indicators and tailored for different transformation archetypes. Acknowledging the links between malnutrition, environmental, and social issues is key for the sustainable development of food systems, in alignment with heterogeneity at smaller scales (i.e. within-country diversities). Finally, more research is needed to uncover comprehensive 'watchpoints' where there are adequate data to quantify shifts in trajectories, in response to targeted efforts to meet Sustainable Development Goals, as they apply to food systems at global, national and regional scales.

Supplementary Information The online version contains supplementary material available at https://doi.org/10.1007/s11625-022-01102-5.

Acknowledgements This paper is a result of the working group "sOcioLock-in", kindly supported by sDiv, the Synthesis Centre of the German Centre for Integrative Biodiversity Research (iDiv) Halle-Jena-Leipzig (DFG FZT 118). We thank all the organizers, participants and administrative staff involved in the sDiv working group sOcioLock-in. This study was financed in part by the Coordenação de Aperfeiçoamento de Pessoal de Nível Superior-Brazil (CAPES)Finance Code 001. André Dornelles is funded by a Brazilian CAPES scholarship.

Author contributions All co-authors contributed to article conceptualization and writing. $\mathrm{AD}$ was responsible for data curation, visualization and writing the original draft. $\mathrm{AD}, \mathrm{TO}, \mathrm{RS}$, and MD designed the methodology, conducted the formal analysis, and verified the underlying data. JS and TO contributed to funding acquisition and article supervision. All authors had full access to all data in the study, participated in discussion and writing and accept responsibility to submit this work for publication.

Funding The funders of the study had no role in study design; in the collection, analysis, and interpretation of data; in the writing of the report; and in the decision to submit the paper for publication.

Data and code availability The authors declare that the data supporting all figures of this study are available within the paper and its supplementary materials. The data that support the findings of this study are available from: the Food and Agriculture Organization of the United Nations (available from http://www.fao.org/faostat/en/\#data), World Development Indicators, from the World Bank (available from https:// databank.worldbank.org/source/world-development-indicators), SDG Indicators database, from the United Nations (available from https:// 
unstats.un.org/sdgs/indicators/database/), Climate Analysis Indicator Tool, from the World Resource Institute (available from https://www. climatewatchdata.org/ghg-emissions?sectors $=512 \% 2 \mathrm{C} 514$ ), the International Labour Organization (available from https://ilostat.ilo.org/ data/), the International Fertilizer Association (available from https:// www.ifastat.org/databases), and the United States Department of Agriculture (available from https://www.ers.usda.gov/data-products/inter national-agricultural-productivity/). Furthermore, the authors declare that the scripts supporting all figures and results of this study are described in the Supplementary materials (Supplementary Table S8) and accession codes are deposited into a public repository: https:// github.com/adornelles/FoodSystemsTransformationArchetypes.

\section{Declarations}

Conflict of interest The authors have no relevant financial or non-financial interests to disclose.

Open Access This article is licensed under a Creative Commons Attribution 4.0 International License, which permits use, sharing, adaptation, distribution and reproduction in any medium or format, as long as you give appropriate credit to the original author(s) and the source, provide a link to the Creative Commons licence, and indicate if changes were made. The images or other third party material in this article are included in the article's Creative Commons licence, unless indicated otherwise in a credit line to the material. If material is not included in the article's Creative Commons licence and your intended use is not permitted by statutory regulation or exceeds the permitted use, you will need to obtain permission directly from the copyright holder. To view a copy of this licence, visit http://creativecommons.org/licenses/by/4.0/.

\section{References}

Abson DJ, Fischer J, Leventon J, Newig J, Schomerus T, Vilsmaier $\mathrm{U}$, von Wehrden H, Abernethy P, Ives CD, Jager NW, Lang DJ (2017) Leverage points for sustainability transformation. Ambio 46(1):30-39. https://doi.org/10.1007/s13280-016-0800-y

Afshin A, Sur PJ, Fay KA, Cornaby L, Ferrara G, Salama JS, Mullany EC, Abate KH, Abbafati C, Abebe Z, Afarideh M, Aggarwal A, Agrawal S, Akinyemiju T, Alahdab F, Bacha U, Bachman VF, Badali H, Badawi A et al (2019) Health effects of dietary risks in 195 countries, 1990-2017: a systematic analysis for the Global Burden of Disease Study 2017. Lancet 393(10184):1958-1972. https://doi.org/10.1016/S0140-6736(19)30041-8

Alexandratos N, Bruinsma J (2012) World agriculture towards 2030/2050: the 2012 revision. http://www.fao.org/3/a-ap106e. pdf.Accessed 10 July 2021

Aschemann-Witzel J (2016) Waste not, want not, emit less. Science 352(6284):408-409. https://doi.org/10.1126/science.aaf2978

Bahadur KK, Dias GM, Veeramani A, Swanton CJ, Fraser D, Steinke D, Lee E, Wittman H, Farber JM, Dunfield K, McCann K, Anand M, Campbell M, Rooney N, Raine NE, Acker RV, Hanner R, Pascoal S, Sharif S et al (2018) When too much isn't enough: does current food production meet global nutritional needs? PLoS ONE 13(10):e0205683. https://doi.org/10.1371/journal.pone.0205683

Beckmann M, Gerstner K, Akin-Fajiye M, Ceaușu S, Kambach S, Kinlock NL, Phillips HRP, Verhagen W, Gurevitch J, Klotz S, Newbold T, Verburg PH, Winter M, Seppelt R (2019) Conventional land-use intensification reduces species richness and increases production: a global meta-analysis. Glob Change Biol 25(6):1941-1956. https://doi.org/10.1111/gcb.14606
Bengtsson M, Alfredsson E, Cohen M, Lorek S, Schroeder P (2018) Transforming systems of consumption and production for achieving the sustainable development goals: moving beyond efficiency. Sustain Sci 13(6):1533-1547. https://doi.org/10.1007/ s11625-018-0582-1

Bentham J, Singh GM, Danaei G, Green R, Lin JK, Stevens GA, Farzadfar F, Bennett JE, Di Cesare M, Dangour AD, Ezzati M (2020) Multidimensional characterization of global food supply from 1961 to 2013. Nat Food 1(1):70-75. https://doi.org/10.1038/ s43016-019-0012-2

Benton TG, Bailey R (2019) The paradox of productivity: agricultural productivity promotes food system inefficiency. Glob Sustain 2:e6. https://doi.org/10.1017/sus.2019.3

Campbell BM, Vermeulen SJ, Aggarwal PK, Corner-Dolloff C, Girvetz E, Loboguerrero AM, Ramirez-Villegas J, Rosenstock T, Sebastian L, Thornton PK, Wollenberg E (2016) Reducing risks to food security from climate change. Glob Food Sec 11:34-43. https:// doi.org/10.1016/j.gfs.2016.06.002

Campbell BM, Beare DJ, Bennett EM, Hall-Spencer JM, Ingram JSI, Jaramillo F, Ortiz R, Ramankutty N, Sayer JA, Shindell D (2017) Agriculture production as a major driver of the earth system exceeding planetary boundaries. Ecol Soc. https://doi.org/10. 5751/ES-09595-220408

Charrad M, Ghazzali N, Boiteau V, Niknafs A (2014) NbClust: an R package for determining the relevant number of clusters in a data set. J Stat Softw. https://doi.org/10.18637/jss.v061.i06

Chaudhary A, Gustafson D, Mathys A (2018) Multi-indicator sustainability assessment of global food systems. Nat Commun 9(1):848. https://doi.org/10.1038/s41467-018-03308-7

Clark M, Tilman D (2017) Comparative analysis of environmental impacts of agricultural production systems, agricultural input efficiency, and food choice. Environ Res Lett. https://doi.org/10. 1088/1748-9326/aa6cd5

Crippa M, Solazzo E, Guizzardi D, Monforti-Ferrario F, Tubiello FN, Leip A (2021) Food systems are responsible for a third of global anthropogenic GHG emissions. Nat Food 2(3):198-209. https:// doi.org/10.1038/s43016-021-00225-9

Cumming GS, Buerkert A, Hoffmann EM, Schlecht E, von CramonTaubadel S, Tscharntke T (2014) Implications of agricultural transitions and urbanization for ecosystem services. Nature 515(7525):50-57. https://doi.org/10.1038/nature13945

Davis KF, Downs S, Gephart JA (2021) Towards food supply chain resilience to environmental shocks. Nat Food 2(1):54-65. https:// doi.org/10.1038/s43016-020-00196-3

Development Initiatives (2020) 2020 Global Nutrition Report: action on equity to end malnutrition. https://globalnutritionreport.org/ reports/2020-global-nutrition-report/

Dornelles AZ, Boyd E, Nunes RJ, Asquith M, Boonstra WJ, Delabre I, Denney JM, Grimm V, Jentsch A, Nicholas KA, Schröter M, Seppelt R, Settele J, Shackelford N, Standish RJ, Yengoh GT, Oliver TH (2020) Towards a bridging concept for undesirable resilience in social-ecological systems. Glob Sustain 3:e20. https://doi.org/ 10.1017/sus.2020.15

Fanzo J, Haddad L, McLaren R, Marshall Q, Davis C, Herforth A, Jones A, Beal T, Tschirley D, Bellows A, Miachon L, Gu Y, Bloem M, Kapuria A (2020) The Food Systems Dashboard is a new tool to inform better food policy. Nat Food 1(5):243-246. https://doi.org/10.1038/s43016-020-0077-y

FAO (2017) The future of food and agriculture. Trends and challenges. http://www.fao.org/3/a-i6583e.pdf

FAO, IFAD, UNICEF, WFP, and WHO (2019) The State of Food Security and Nutrition in the World 2019. Safeguarding against economic slowdowns and downturns. http://www.fao.org/3/ca516 2en/ca5162en.pdf 
FAO, IFAD, UNICEF, WFP, and WHO (2020) The State of Food Security and Nutrition in the World 2020. Transforming food systems for affordable healthy diets. https://doi.org/10.4060/ca9692en

Fears R, Canales C, ter Meulen V, von Braun J (2019) Transforming food systems to deliver healthy, sustainable diets - the view from the world's science academies. Lancet Planet Health 3(4):e163e165. https://doi.org/10.1016/S2542-5196(19)30038-5

Fowler D, Coyle M, Skiba U, Sutton MA, Cape JN, Reis S, Sheppard LJ, Jenkins A, Grizzetti B, Galloway JN, Vitousek P, Leach A, Bouwman AF, Butterbach-Bahl K, Dentener F, Stevenson D, Amann M, Voss M (2013) The global nitrogen cycle in the twentyfirst century. Philos Trans R Soc b Biol Sci 368(1621):20130164. https://doi.org/10.1098/rstb.2013.0164

Friel S, Schram A, Townsend B (2020) The nexus between international trade, food systems, malnutrition and climate change. Nat Food 1(1):51-58. https://doi.org/10.1038/s43016-019-0014-0

Hadjikakou M, Ritchie EG, Watermeyer KE, Bryan BA (2019) Improving the assessment of food system sustainability. Lancet Planet Health 3(2):e62-e63. https://doi.org/10.1016/S2542-5196(18) 30244-4

IFPRI (2015) Global nutrition report 2015: actions and accountability to advance nutrition and sustainable development. https://doi.org/ $10.2499 / 9780896298835$

IPCC 2014) Climate change 2014: synthesis report. Contribution of working groups I, II and III to the fifth assessment report of the intergovernmental panel on climate change. https://www.ipcc.ch/ pdf/assessment-report/ar5/syr/SYR_AR5_FINAL_full_wcover. pdf

Kummu M, Kinnunen P, Lehikoinen E, Porkka M, Queiroz C, Röös E, Troell M, Weil C (2020) Interplay of trade and food system resilience: Gains on supply diversity over time at the cost of trade independency. Glob Food Sec 24:100360. https://doi.org/10. 1016/j.gfs.2020.100360

Lindgren E, Harris F, Dangour AD, Gasparatos A, Hiramatsu M, Javadi F, Loken B, Murakami T, Scheelbeek P, Haines A (2018) Sustainable food systems - a health perspective. Sustain Sci 13(6):15051517. https://doi.org/10.1007/s11625-018-0586-x

Marshall Q, Fanzo J, Barrett CB, Jones AD, Herforth A, McLaren R (2021) Building a global food systems typology: a new tool for reducing complexity in food systems analysis. Front Sustain Food Syst. https://doi.org/10.3389/fsufs.2021.746512

Matsuyama K (1992) Agricultural productivity, comparative advantage, and economic growth. J Econ Theory 58(2):317-334. https:// doi.org/10.1016/0022-0531(92)90057-O

Nyström M, Jouffray J-B, Norström AV, Crona B, Søgaard Jørgensen P, Carpenter SR, Bodin Ö, Galaz V, Folke C (2019) Anatomy and resilience of the global production ecosystem. Nature 575(7781):98-108. https://doi.org/10.1038/s41586-019-1712-3

Oliver TH, Boyd E, Balcombe K, Benton TG, Bullock JM, Donovan D, Feola G, Heard M, Mace GM, Mortimer SR, Nunes RJ, Pywell RF, Zaum D (2018) Overcoming undesirable resilience in the global food system. Glob Sustain 1:e9. https://doi.org/10.1017/ sus.2018.9

Oliver TH, Benini L, Borja A, Dupont C, Doherty B, GrodzińskaJurczak M, Iglesias A, Jordan A, Kass G, Lung T, Maguire C, McGonigle D, Mickwitz P, Spangenberg JH, Tarrason L (2021) Knowledge architecture for the wise governance of sustainability transitions. Environ Sci Policy 126:152-163. https://doi.org/10. 1016/j.envsci.2021.09.025

Ortiz-Bobea A, Ault TR, Carrillo CM, Chambers RG, Lobell DB (2021) Anthropogenic climate change has slowed global agricultural productivity growth. Nat Clim Chang 11(4):306-312. https:// doi.org/10.1038/s41558-021-01000-1

Paine CET, Marthews TR, Vogt DR, Purves D, Rees M, Hector A, Turnbull LA (2012) How to fit nonlinear plant growth models and calculate growth rates: an update for ecologists. Methods
Ecol Evol 3(2):245-256. https://doi.org/10.1111/j.2041-210X. 2011.00155.x

Pilling D, Bélanger J, Hoffmann I (2020) Declining biodiversity for food and agriculture needs urgent global action. Nat Food 1(3):144-147. https://doi.org/10.1038/s43016-020-0040-y

Poore J, Nemecek T (2018) Reducing food's environmental impacts through producers and consumers. Science 360(6392):987-992. https://doi.org/10.1126/science.aaq0216

Pradhan P, Costa L, Rybski D, Lucht W, Kropp JP (2017) A systematic study of sustainable development goal (SDG) interactions. Earth's Future 5(11):1169-1179. https://doi.org/10.1002/2017EF000632

Pradyumna A (2018) Planetary health and food systems: insights from global SDGs. Lancet Planet Health 2(10):e417-e418. https://doi. org/10.1016/S2542-5196(18)30202-X

Prajneshu, Chandran KP (2005) Computation of compound growth rate in agriculture: revisited. Agric Econ Res Rev 18:317-324. https:// ageconsearch.umn.edu/record/58480/files/art-13.pdf

Ruttan VW (1977) Induced innovation and agricultural development. Food Policy 2(3):196-216. https://doi.org/10.1016/0306-9192(77) 90080-X

Schipper AM, Hilbers JP, Meijer JR, Antão LH, Benítez-López A, Jonge MMJ, Leemans LH, Scheper E, Alkemade R, Doelman JC, Mylius S, Stehfest E, Vuuren DP, Zeist W, Huijbregts MAJ (2020) Projecting terrestrial biodiversity intactness with GLOBIO 4. Glob Change Biol 26(2):760-771. https://doi.org/10.1111/gcb. 14848

Seekell D, Carr J, Dell'Angelo J, D’Odorico P, Fader M, Gephart J, Kummu M, Magliocca N, Porkka M, Puma M, Ratajczak Z, Rulli MC, Suweis S, Tavoni A (2017) Resilience in the global food system. Environ Res Lett 12(2):025010. https://doi.org/10.1088/ 1748-9326/aa5730

Seppelt R, Arndt C, Beckmann M, Martin EA, Hertel TW (2020) Deciphering the biodiversity-production mutualism in the global food security debate. Trends Ecol Evol 35(11):1011-1020. https://doi. org/10.1016/j.tree.2020.06.012

Springmann M, Clark M, Mason-D'Croz D, Wiebe K, Bodirsky BL, Lassaletta L, de Vries W, Vermeulen SJ, Herrero M, Carlson KM, Jonell M, Troell M, DeClerck F, Gordon LJ, Zurayk R, Scarborough P, Rayner M, Loken B, Fanzo J et al (2018a) Options for keeping the food system within environmental limits. Nature 562(7728):519-525. https://doi.org/10.1038/s41586-018-0594-0

Springmann M, Wiebe K, Mason-D’Croz D, Sulser TB, Rayner M, Scarborough P (2018b) Health and nutritional aspects of sustainable diet strategies and their association with environmental impacts: a global modelling analysis with country-level detail. Lancet Planet Health 2(10):e451-e461. https://doi.org/10.1016/ S2542-5196(18)30206-7

Stirzaker R, Biggs H, Roux D, Cilliers P (2010) Requisite simplicities to help negotiate complex problems. Ambio 39(8):600-607. https://doi.org/10.1007/s13280-010-0075-7

Sukhdev P (2018) Smarter metrics will help fix our food system. Nature 558(7708):7-7. https://doi.org/10.1038/d41586-018-05328-1

TEEB (2018) The Economics of Ecosystems and Biodiversity (TEEB): Measuring what matters in agriculture and food systems: a synthesis of the results and recommendations of TEEB for Agriculture and Food's Scientific and Economic Foundations report. http:// teebweb.org/agrifood/measuring-what-matters-in-agricultureand-food-systems/

Whitmee S, Haines A, Beyrer C, Boltz F, Capon AG, de Souza Dias BF, Ezeh A, Frumkin H, Gong P, Head P, Horton R, Mace GM, Marten R, Myers SS, Nishtar S, Osofsky SA, Pattanayak SK, Pongsiri MJ, Romanelli C et al (2015) Safeguarding human health in the Anthropocene epoch: report of The Rockefeller Foundation-Lancet Commission on planetary health. Lancet 386(10007):1973-2028. https://doi.org/10.1016/S0140-6736(15) 60901-1 
Willett W, Rockström J, Loken B, Springmann M, Lang T, Vermeulen S, Garnett T, Tilman D, DeClerck F, Wood A, Jonell M, Clark M, Gordon LJ, Fanzo J, Hawkes C, Zurayk R, Rivera JA, De Vries W, Majele Sibanda L et al (2019) Food in the Anthropocene: the EAT-Lancet Commission on healthy diets from sustainable food systems. Lancet. https://doi.org/10.1016/S0140-6736(18)31788-4

Zabel F, Delzeit R, Schneider JM, Seppelt R, Mauser W, Václavík T (2019) Global impacts of future cropland expansion and intensification on agricultural markets and biodiversity. Nat Commun 10(1):2844. https://doi.org/10.1038/s41467-019-10775-z
Zurek M, Hebinck A, Leip A, Vervoort J, Kuiper M, Garrone M, Havlík P, Heckelei T, Hornborg S, Ingram J, Kuijsten A, Shutes L, Geleijnse J, Terluin I, van't Veer P, Wijnands J, Zimmermann A, Achterbosch T (2018) Assessing Sustainable Food and Nutrition Security of the EU Food System - an integrated approach. Sustainability 10(11):4271. https://doi.org/10.3390/su10114271

Publisher's Note Springer Nature remains neutral with regard to jurisdictional claims in published maps and institutional affiliations.

\section{Authors and Affiliations}

\section{André Zuanazzi Dornelles ${ }^{1,2} \mathbb{D} \cdot$ Wiebren J. Boonstra ${ }^{3,4} \cdot$ Izabela Delabre $^{5} \cdot$ J. Michael Denney ${ }^{6} \cdot$ Richard J. Nunes $^{2}$. Anke Jentsch ${ }^{7} \cdot$ Kimberly A. Nicholas $^{8} \cdot$ Matthias Schröter $^{9,10} \cdot$ Ralf Seppelt $^{10,11,12} \cdot$ Josef Settele $^{12,13,14}$. Nancy Shackelford ${ }^{15} \cdot$ Rachel J. Standish ${ }^{16} \cdot$ Tom H. Oliver $^{1}$}

1 Ecology and Evolutionary Biology, School of Biological Sciences, University of Reading, Health and Life Sciences Building, Reading RG6 6AS, UK

2 Department of Real Estate and Planning, Henley Business School, University of Reading, Reading, UK

3 Stockholm Resilience Centre, Stockholm University, Stockholm, Sweden

4 Natural Resources and Sustainable Development, Department of Earth Science, Uppsala University, Uppsala, Sweden

5 Department of Geography, Birkbeck, University of London, London, UK

6 Center for Governance and Sustainability, University of Massachusetts Boston, Boston, USA

7 Disturbance Ecology and Vegetation Dynamics, Bayreuth Center of Ecology and Environmental Research (BayCEER), University of Bayreuth, Bayreuth, Germany

8 Lund University Centre for Sustainability Studies (LUCSUS), Lund, Sweden
9 Social-Ecological Systems Institute, Faculty of Sustainability, Leuphana University Lüneburg, Universitätsallee 1, 21335 Lüneburg, Germany

10 Computational Landscape Ecology, Helmholtz Centre for Environmental Research-UFZ, Leipzig, Germany

11 Institute of Geoscience and Geography, Martin-Luther-University Halle-Wittenberg, Halle, Saale, Germany

12 German Centre for Integrative Biodiversity Research (iDiv), Halle-Jena-Leipzig, Leipzig, Germany

13 Helmholtz Centre for Environmental Research-UFZ, Conservation Biology, Halle, Germany

14 Institute of Biological Sciences, College of Arts and Sciences, University of the Philippines, Los Baños, College, Laguna, Philippines

15 Institute of Arctic and Alpine Research, University of Colorado at Boulder, Boulder, USA

16 Environmental and Conservation Sciences, Murdoch University, Perth, WA, Australia 